\title{
INFLUÊNCIA DE VÁLVULAS ARTIFICIAIS SOBRE A MORFOMETRIA INTESTINAL DE RATOS
}

INFLUENCE OF ARTIFICIAL VALVES ON THE INTESTINAL MORPHOLOGY OF RATS

\author{
Maria Cristina Vasconcelos Furtado'; Alcino Lázaro da Silva ECBC MG²; \\ Cícero de Lima Rena TCBC MG3; Ângela Aparecida Barra TCBC MG'; \\ Angela Maria Gonçalves Felga ; Floripes Maria Cardoso Rossman ${ }^{6}$
}

\begin{abstract}
RESUMO: Objetivo: Avaliar o papel de válvulas artificiais constituídas por seromiotomias circunferenciais duplas no comprimento dos vilos, no diâmetro do intestino delgado e no peso de ratos. Método: Foram utilizados 40 ratos, distribuídos em quatro grupos. Os animais do Grupo R foram submetidos à ressecção de $50 \%$ do intestino delgado, sem criação de válvulas. No Grupo RV associaram duas válvulas à ressecção intestinal. No Grupo $\mathrm{V}$ foram criadas duas válvulas, sem ressecção intestinal. $\mathrm{O}$ Grupo $\mathrm{C}$ forneceu a altura normal dos vilos. A eutanásia deu-se entre o décimo e o $14^{\circ}$ dia pós-operatórios. Resultados: Houve aumento no comprimento dos vilos nos grupos R, RV e V. Comparado ao Grupo R, o comprimento dos vilos nos grupos RV e V foi semelhante nos segmentos proximal e distal. No Grupo RV, os vilos do segmento proximal tiveram comprimento superior ao do distal. No Grupo V, o comprimento dos vilos do segmento proximal foi menor que do distal. A alça intestinal teve diâmetro maior que no pré-operatório no Grupo R e nos segmentos proximal à primeira válvula e distal à segunda, dos grupos RV e V. A ressecção intestinal levou à perda ponderal nos grupos R e RV, sem diferença entre os grupos. No Grupo V houve ganho de peso, significativo quando comparado aos grupos R e RV. Apesar de não impedirem a perda ponderal em animais submetidos à ressecção, as válvulas não determinaram perda superior à da ressecção isolada. Conclusão: Essas válvulas parecem influenciar positivamente a adaptação intestinal e podem ser incluídas entre as técnicas de reabilitação intestinal cirúrgica, isoladamente ou precedendo intervenções de alongamento do intestino (Rev. Col. Bras. Cir. 2008; 35(5): 315-322).
\end{abstract}

Descritores: Intestino Delgado; Síndrome do Intestino Curto; Esfíncter artificial; Ressecção intestinal; Mucosa intestinal

\section{INTRODUÇÃO}

A perda da função intestinal significa a incapacidade de manter, por via enteral, um estado nutricional apropriado. Resultante de uma série de agravos, congênitos e adquiridos, agudos ou crônicos, é geradora de grandes angústias para o paciente, para sua família e para a equipe médica. Adultos temem por sua qualidade de vida, enfrentam dificuldades na vida social e nas atividades profissionais. Às crianças soma-se ainda o desafio de alcançar crescimento e desenvolvimento, se não normais, ao menos adequados. A perda da autonomia enteral é devastadora em qualquer idade.

O advento da nutrição parenteral total (NPT) por Dudrick e Wilmore, permitiu maior sobrevida dos pacientes, muitos deles alcançando a adaptação intestinal. Embora muitos possam migrar da dieta intravenosa para a enteral, um grande número dependerá total ou parcialmente da NPT. Na prática, isto resulta em custos financeiros elevados, uma variedade de complicações e comprometimentos da vida social.
São freqüentes os problemas com os acessos vasculares, a sepse por cateter e disfunções orgânicas crônicas, como deterioração das funções renal e hepática ${ }^{1}$.

$O$ processo de adaptação pode ser acelerado e intensificado por meio da combinação de intervenções nutricionais e não-nutricionais. Nutrimentos específicos são introduzidos em dietas manipuladas, aprimorando a adaptação intestinal, possivelmente com mediação de secreções gastrintestinais e fatores de crescimento. Embora dados clínicos oriundos de observações em humanos se restrinjam aos efeitos do hormônio do crescimento, do peptídeo semelhante ao glucagon 2 e do fator de crescimento epidérmico, outros fatores de crescimento mostram-se efetivos em experimentos com animais. As técnicas cirúrgicas que visam aprimorar a adaptação intestinal são denominadas de reabilitação intestinal cirúrgica ou de reconstrução gastrintestinal autógena. As mais utilizadas são as técnicas de alongamento intestinal, por vezes associadas às válvulas e à reversão de segmentos intestinais $^{2-5}$.

\footnotetext{
1. Professora do Departamento de Morfologia da Universidade Federal de Juiz de Fora; Cirurgiã Geral da Santa Casa de Misericórdia da Santa Casa de Misericórdia de Juiz de Fora; Doutoranda em Cirurgia na UFMG.

2. Professor Titular de Cirurgia da Faculdade de Medicina da Universidade Federal de Minas Gerais.

3. Professor Adjunto IV de Cirurgia da Faculdade de Medicina da Universidade Federal de Juiz de Fora; Mestre em Técnica Cirúrgica e Cirurgia Experimental. Doutor em Cirurgia na UFMG.

4. Cirurgiã Geral da Santa Casa de Misericórdia de Juiz de Fora; Doutoranda em Cirurgia na UFMG.

5. Professora da Faculdade de Ciências Médicas e da Saúde de Juiz de Fora; Mestre em Patologia pela Universidade Federal Fluminense.

6. Professora do Departamento de Morfologia da Universidade Federal de Juiz de Fora.
}

Recebido em 28/05/2008

Aceito para publicação em 05/07/2008

Conflito de interesses: nenhum

Fonte de financiamento: nenhuma

Trabalho realizado no Centro de Biologia de Reprodução da Universidade Federal de Juiz de Fora - MG. 
Atualmente, considera-se apropriado oferecer aos pacientes técnicas de reconstrução gastrintestinal autógena antes do transplante intestinal. Reconstrução gastrintestinal autógena e transplante não são antagônicos, mas mutuamente complementares. Mesmo que não permitam alcançar a autonomia enteral, as operações de reabilitação intestinal facilitam a interrupção ou reduzem a necessidade da NPT. Complicações como as doenças hepáticas, sepse recorrente e limitação de acesso vascular relacionadas à nutrição venosa são evitadas, controladas ou revertidas. Isso poderá evitar um transplante combinado de fígado e intestino ou diminuir o risco cirúrgico do transplantado ${ }^{3,4}$.

A redução da velocidade do trânsito intestinal pela criação de dispositivos de rápida e fácil execução incentivou estudos de válvulas artificiais por seromiotomias circunferenciais. Com o advento do conceito de reabilitação intestinal cirúrgica vislumbrou-se a possibilidade de incluir esse tipo de válvula entre suas técnicas. Publicações anteriores evidenciaram a capacidade dessas válvulas de retardarem o trânsito intestinal, sem ocasionar obstrução. Desconhecemse, no entanto, suas interferências na adaptação intestinal ${ }^{6-9}$. O presente trabalho visa avaliar as alterações morfométricas das vilosidades intestinais de ratos submetidos à criação cirúrgica dessas válvulas.

\section{MÉTODO}

Foram utilizados nos experimentos 40 ratos Wistar (Rattus norvegicus albinus, Berkenhout, 1769), machos e adultos (com mais de quatro meses de vida), obtidos na colônia do biotério do Centro de Biologia da Reprodução (CBR), da Universidade Federal de Juiz de Fora (UFJF). Os pesos variaram entre $201 \mathrm{~g}$ e $314 \mathrm{~g}(\mathrm{M} \pm \mathrm{DPM}: 260 \pm 30 \mathrm{~g})$.

Os ratos foram aleatoriamente divididos em grupos de 10 animais: No Grupo R procedeu-se a ressecção de 50\% do intestino delgado, sem criação de válvulas. Nos animais do Grupo RV foi ressecado 50\% do intestino delgado, com criação de duas válvulas, por meio de seromiotomias circunferenciais duplas. Duas válvulas, idênticas às anteriores, foram criadas nos animais do Grupo V, porém sem ressecção intestinal. A fim de realizar comparação do comprimento dos vilos no segmento correspondente aos $15 \mathrm{~cm}$ terminais do intestino delgado foi criado um grupo controle (Grupo C). A utilização dos próprios animais dos grupos de ressecção não seria viável, uma vez que as ressecções englobavam porções mais altas do intestino delgado. Os animais do Grupo $\mathrm{C}$ foram submetidos à ressecção de um segmento de $2 \mathrm{~cm}$ de alça intestinal, distando $10 \mathrm{~cm}$ da válvula ileocecal.

Na noite que antecedia o ato cirúrgico, sempre realizado na parte da manhã, apenas água com açúcar $(5 \mathrm{gr}$ em $200 \mathrm{~mL}$ de água) era oferecida aos animais. Depois de pesados, os ratos eram anestesiados por meio da injeção intraperitoneal de $10 \mathrm{mg} / \mathrm{kg}$ de xilazina, associadas a $90 \mathrm{mg} / \mathrm{kg}$ de ketamina ${ }^{10}$. Uma incisão abdominal mediana, de $3 \mathrm{~cm}$, abrangia pele e tela subcutânea. Os músculos eram separados no plano mediano e a cavidade peritoneal era alcançada e as transições gastroduodenal e íleocólica identificadas.

Nos animais do Grupo R, o intestino delgado era medido ao longo da face antimesentérica, do piloro à válvula ileocecal, com um fio cirúrgico, sem submeter a alça à tensão longitudinal ${ }^{11}$. A $10 \mathrm{~cm}$ da válvula ileocecal procedia-se à medida do diâmetro do intestino delgado. A porção ressecada era pesada e o valor obtido, subtraído do peso pré-operatório. $\mathrm{O}$ peso obtido foi o considerado como peso inicial para os animais com ressecção intestinal. Três centímetros após o ângulo duodenojejunal eram ressecados $50 \%$ do intestino delgado. Uma anastomose término-terminal, em plano único, com fio 7.0 de poligalactina 910 , reconstituía o trânsito.

No Grupo RV, o comprimento do intestino delgado era medido à maneira descrita para o Grupo R. A medida do diâmetro da alça era feita em dois pontos, a $10 \mathrm{~cm}$ e $15 \mathrm{~cm}$ da válvula ileocecal, locais da execução das seromiotomias. A porção ressecada era pesada e o valor obtido, subtraído do peso pré-operatório. Depois da ressecção de $50 \%$ do intestino delgado, a partir de $3 \mathrm{~cm}$ do ângulo duodenojejunal, procedia-se a anastomose términoterminal em plano único com fio 7.0 de poligalactina 910 . Duas válvulas, cada uma delas resultado de seromiotomias circunferenciais duplas, foram criadas a $10 \mathrm{~cm}$ e $15 \mathrm{~cm}$ da válvula ileoceca, proximalmente. Em cada seromiotomia, as camadas serosa e musculares eram incisadas cincunferencialmente, exceto na face mesentérica da alça intestinal, mantendo-se íntegra a camada mucosa. Dois milímetros de parede intestinal íntegra separava as seromiotomias. A borda cruenta proximal da seromiotomia cranial era suturada à borda cruenta distal da seromiotomia caudal com fio 7.0 de poligalactina 910, pontos separados. Assim constituíase uma primeira válvula, a $15 \mathrm{~cm}$ da junção ileocecocólica. A segunda válvula, idêntica à primeira, era criada $5 \mathrm{~cm}$ após esta, ou seja, à $10 \mathrm{~cm}$ da válvula ileocecal. Um segmento intermediário, de $5 \mathrm{~cm}$, ficou interposto às válvulas.

Nos animais do Grupo V, os diâmetros da alça intestinal foram aferidos da mesma forma descrita para o Grupo RV. Sem realizar ressecção intestinal, duas válvulas idênticas às do Grupo RV foram criadas.

A fim de realizar comparação do comprimento dos vilos e o diâmetro da alça intestinal no segmento correspondente aos $15 \mathrm{~cm}$ terminais do intestino delgado foi criado um grupo controle (Grupo C). Neste grupo realizou-se apenas a ressecção de um segmento de $2 \mathrm{~cm}$ de alça intestinal, distando $10 \mathrm{~cm}$ da válvula ileocecal. Os animais foram mortos imediatamente após o procedimento.

Durante o período pós-operatório, os animais eram mantidos em gaiolas aquecidas. $\mathrm{O}$ analgésico (paracetamol, $100 \mathrm{mg} / \mathrm{kg}$ ) era dissolvido em água e oferecido de forma contínua ${ }^{10}$. Os animais recebiam apenas água no primeiro dia pósoperatório. Nos dois dias seguintes, os ratos recebiam ração umedecida em água e triturada. No quarto dia a alimentação pastosa era substituída por ração seca.

A relaparotomia ocorreu entre o décimo e o $14^{\circ}$ dia pós-operatório. Os ratos eram pesados e anestesiados com dose dobrada da quantidade de anestésicos calculada para seus pesos (dose letal). Com a cavidade peritoneal aberta, procedia-se a lise das aderências e a identificação das anastomoses nos Grupos R e RV e das válvulas nos Grupos RV e V. Media-se o diâmetro das alças intestinais nos seguintes pontos: no Grupo R, a 10cm da junção ileocecal; nos Grupo $\mathrm{RV}$ e V, a $1 \mathrm{~cm}$ das válvulas proximal e distal, no sentido oral da válvula proximal e aboral da válvula distal. 
O estudo morfométrico foi realizado por meio do programa "AxioVision 3.1.2.1". As fotomicrografias foram feitas com uma câmara fotográfica Carl Zeiss AxioCam - Version 5.05.10, acoplada a um microscópio "Zeiss Axiostar Plus" e objetiva: $5 \mathrm{X} / 0,12$. Foi medida a altura de cinco vilosidades íntegras de cada fragmento ileal estudado. Em uma secção longitudinal, as alturas das vilosidades eram mensuradas traçando-se uma linha na base de cada vilosidade, unindo criptas vizinhas (junção vilo-cripta). A seguir, uma segunda linha, percorrendo o maior eixo da vilosidade, era traçada, ligando o ápice da vilosidade à linha de base. Nos grupos $\mathrm{R}$ e $\mathrm{C}$ um único conjunto de cinco vilosidades foi estudado. Nos Grupos V e RV foram estudados dois segmentos intestinais: o segmento que imediatamente precedia a válvula proximal e aquele imediatamente após a válvula distal.

Para análise estatística descritiva foram calculadas a média e o desvio-padrão da média das variáveis: peso dos animais, diâmetro do intestino e comprimento dos vilos. Para comparação das variáveis peso, diâmetro da alça e comprimento dos vilos entre os grupos foi utilizado o teste " $t$ " para amostras independentes. Quando foram realizadas comparações dentro de cada grupos dos achados do pré-operatório com os do pósoperatório (peso e diâmetro da alça intestinal) e dos segmentos pré e pós-válvulas (diâmetro da alça intestinal e comprimento dos vilos) recorreu-se ao teste " $t$ " para amostras pareadas. A análise de variância (ANOVA) foi utilizada para a comparação, entre os grupos, dos diâmetros distal e proximal no pós-operatório. O nível de significância adotado foi de $5 \%$.

\section{RESULTADOS}

No Grupo R, o comprimento médio dos vilos no segmento intestinal a $10 \mathrm{~cm}$ da válvula ileocecal foi de 422,8 $\pm 180,1 \mathrm{~m} \mu$. Nos animais do Grupo RV, o comprimento médio dos vilos no segmento intestinal proximal à primeira válvula foi de 423,8 $\pm 119 \mathrm{~m} \mu$. No segmento distal à segunda válvula, foi de $361,3 \pm 99,3 \mathrm{~m} \mu$. No Grupo $\mathrm{V}$, os vilos proximais à primeira válvula tiveram comprimento médio de $396,6 \pm 65,1 \mathrm{~m} \mu$ e os distais à segunda válvula, 407,7 $\pm 77,7 \mathrm{~m} \mu$. No Grupo C o comprimento médio dos vilos no segmento intestinal a $10 \mathrm{~cm}$ da válvula ileocecal foi de $272 \pm 26,6 \mathrm{~m} \mu$, inferior ao do Grupo $\mathrm{R}$ (p $=0,03$ ), segmentos proximal e distal do Grupo RV (respectivamente, $\mathrm{p}=0,003$ e $\mathrm{p}=0,02)$ e segmentos proximal e distal do Grupo V (ambos com p =0,000). (Tabela 1 e Figuras 1 a 6)

O comprimento médio dos vilos dos animais do Grupo $\mathrm{R}(422,8 \pm 180,1 \mathrm{~m} \mu)$ não foi diferente do comprimento médio dos vilos dos segmentos proximal $(423,8 \pm 119 \mathrm{~m} \mu, \mathrm{p}=0,99) \mathrm{e}$ distal $(361,3 \pm 99,3 \mathrm{~m} \mu, \mathrm{p}=0,36)$ do Grupo RV.

Não houve diferença entre o comprimento dos vilos do Grupo R $(422,8 \pm 180,1 \mathrm{~m} \mu)$ e os segmentos proximal $(396,6 \pm$ $65,1 \mathrm{~m} \mu, \mathrm{p}=0,68)$ e distal $(407,7 \pm 77,7 \mathrm{~m} \mu, \mathrm{p}=0,81)$ do Grupo V.

O comprimento médio dos vilos não foi diferente entre os segmentos proximais nos animais do Grupo RV (423,8 \pm $119 \mathrm{~m} \mu)$ e V $(396,6 \pm 65,1 \mathrm{~m} \mu)(\mathrm{p}=0,53)$. O mesmo ocorreu quando a comparação foi feita para os segmentos distais dos grupos RV $(361,3 \pm 99,3 \mathrm{~m} \mu)$ e V $(407,7 \pm 77,7 \mathrm{~m} \mu)$, com $\mathrm{p}=0,26$.

No Grupo RV, os vilos do segmento proximal tiveram comprimento médio $(423,8 \pm 119 \mathrm{~m} \mu)$ superior ao do segmento distal $(361,3 \pm 99,3 \mathrm{~m} \mu)$, sendo essa diferença significativa $(\mathrm{p}=$ $0,02)$. Ao contrário, no Grupo $\mathrm{V}$, o comprimento médio dos vilos do segmento proximal $(396,6 \pm 65,1 \mathrm{~m} \mu)$ foi menor que o do segmento distal $(407,7 \pm 77,7 \mathrm{~m} \mu)$, porém essa diferença não foi significativa $(\mathrm{p}=0,54)$.

No pós-operatório ocorreu dilatação da alça intestinal nos três grupos. No Grupo R, o diâmetro médio do intestino na região correspondente àquela com as válvulas nos grupos RV e V foi maior que no pré-operatório $(8,7 \pm 1,9 \mathrm{~mm})$. Houve diferença entre as duas avaliações $(p=0,000)$. Nos

Tabela 1 - Comprimento médio dos vilos, em milimicra, nos animais dos grupos $R, R V$ e $V$.

\begin{tabular}{lccccc}
\hline Animal & Grupo R & \multicolumn{2}{c}{ Grupo RV } & \multicolumn{2}{c}{ GrupoV } \\
\cline { 3 - 6 } & & Segmento proximal & Segmento distal & Segmento proximal & Segmento distal \\
\hline 1 & 289,3 & 456,7 & 425,7 & 338,5 & 317,0 \\
2 & 139,4 & 462,3 & 363,3 & 407,4 & 399,2 \\
3 & 249,3 & 489,5 & 519,3 & 4874 & 529,9 \\
4 & 546,5 & 538,6 & 472,4 & 440,3 & 433,5 \\
5 & 647,5 & 253,2 & 282,4 & 357,1 & 501,7 \\
6 & 537,4 & 360,0 & 246,0 & 505,7 & 493,1 \\
7 & 252,1 & 652,0 & 557,5 & 395,6 & 357 \\
8 & 399,5 & 370,2 & 262,0 & 358,1 & 376,7 \\
9 & 627,4 & 311 & 305,1 & 300,6 & 335,4 \\
10 & 538,3 & 344,2 & 279,8 & 376,1 & 333,2 \\
Mínimo & 139,4 & 253,2 & 246 & 300,6 & 317,0 \\
Máximo & 647,5 & 652,0 & 519,3 & 505,7 & 529,9 \\
M.DPM & $422,8 \pm 180,1$ & $423,8 \pm 119$ & $361,3 \pm 99,3$ & $396,6 \pm 65,1$ & $407,7 \pm 77,7$ \\
\hline
\end{tabular}

Grupo R: animais submetidos à ressecção simples.

Grupo RV: animais submetidos à ressecção e criação de duas válvulas.

Grupo V: animais submetidos apenas à criação de duas válvulas.

M DPM: média e desvio-padrão da média. 


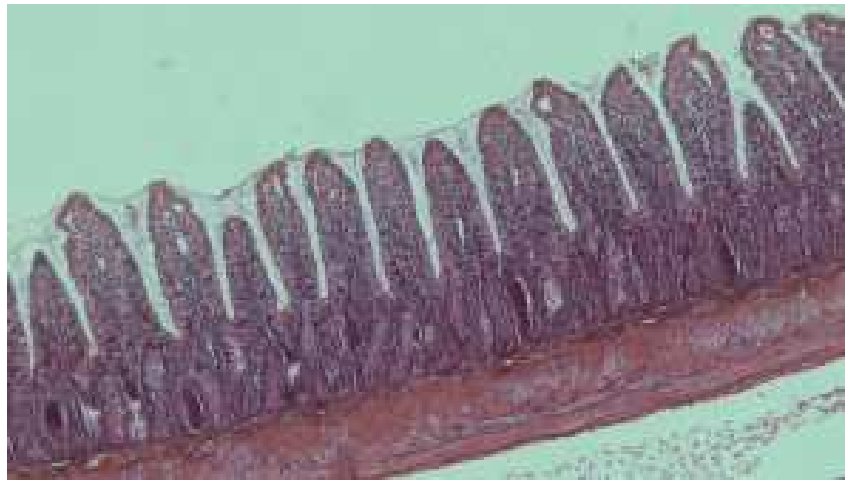

Figura 1 - Fotomicrografia dos vilos intestinais normais. Animal do Grupo C (controle). HE, $5 X$.

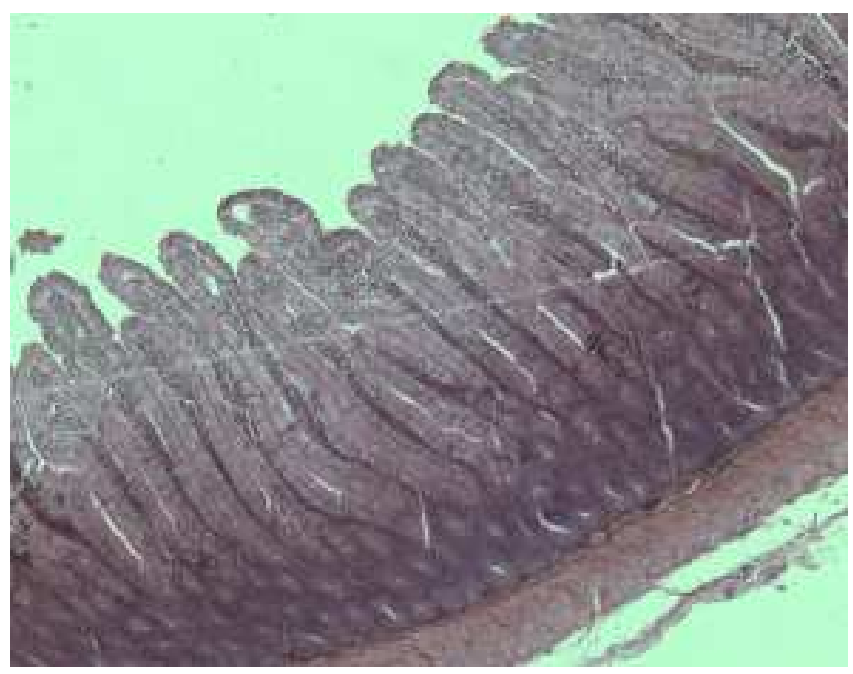

Figura 2 - Fotomicrografia dos vilos intestinais alongados após ressecção intestinal, sem criação de válvula (Grupo R). HE, 5X.

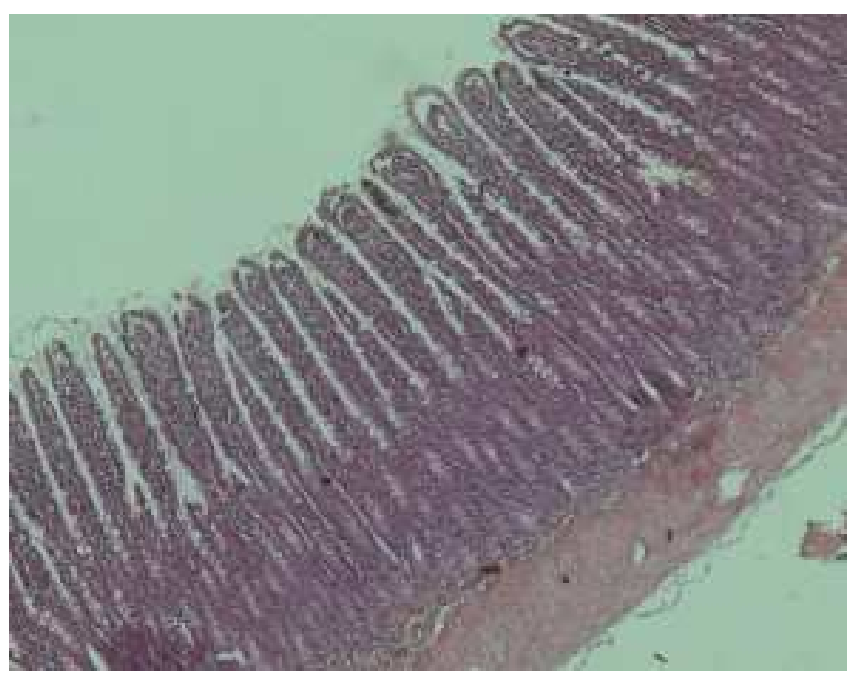

Figura 3 - Fotomicrografia dos vilos intestinais alongados em animal submetido à confecção de válvula, sem ressecção intestinal (Grupo $V$ ). Aspecto do segmento intestinal proximal à primeira válvula. $H E, 5 X$.

animais do Grupo RV, o diâmetro médio do intestino no segmento proximal à primeira válvula foi de $9,3 \pm 0,95 \mathrm{~mm}$. No segmento distal à segunda válvula foi de $8,5 \pm 0,7 \mathrm{~mm}$. Houve diferença entre o pré e o pós-operatório de cada segmento, todas com $\mathrm{p}=0,000$. Nos animais do Grupo $\mathrm{V}$, o diâmetro médio do intestino no segmento proximal à primeira válvula foi de $7,2 \pm 2,2 \mathrm{~mm}$. No segmento distal à segunda válvula $\mathrm{o}$ diâmetro médio foi de $6,8 \pm 2,1 \mathrm{~mm}$. Houve diferença entre o pré e o pós-operatório, com $\mathrm{p}=0,000$ para o segmento proximal e $\mathrm{p}=0,002$ para o segmento distal. Não houve diferença entre os três grupos nas dilatações pós-operatórias nos segmentos proximal $(p=0,61)$ e distal $(p=0,096)$.

Nos animais do Grupo R, a média de peso no pósoperatório foi $249 \pm 39 \mathrm{~g}$, enquanto nos do Grupo RV foi de 259 $\pm 35 \mathrm{~g}$ e de $294 \pm 27 \mathrm{~g}$ nos do Grupo V. Apenas o Grupo V ganhou peso $(12,7 \pm 9,2 \mathrm{~g})$ e esse ganho foi significativo $(\mathrm{p}=$ $0,002)$. O ganho de peso no Grupo V também foi significativo quando comparado aos grupos $\mathrm{R}$ e $\mathrm{RV}$, que perderam peso $(\mathrm{p}=$ 0,01 e $\mathrm{p}=0,005$, respectivamente). A média de perda de peso no Grupo R foi de $-6,4 \pm 18,7 \mathrm{~g}(\mathrm{p}=0,31)$ e no Grupo RV, $-11,1 \pm$ $17,2 \mathrm{~g}(\mathrm{p}=0,11)$, sem diferença entre os grupos $(\mathrm{p}=0,58)$.

\section{DISCUSSÃO}

Em seu uso clássico, as válvulas artificiais são aplicáveis em pacientes com superfície absortiva suficiente porém com trânsito intestinal acelerado ${ }^{12,13}$. Vários tipos de válvulas foram criados: por meio de constrição externa, desnervação, intussuscepção, tunelização submucosa, miectomias, seromiectomias ou por seromiotomias ${ }^{6,7,14,15-17}$. A criação cirúrgica de válvulas artificiais reduz a velocidade do trânsito intestinal e, por aumentar o tempo de contato do quimo com a mucosa do intestino, beneficia a absorção e promove algum grau de dilatação ${ }^{4}$.

A dilatação intestinal por meio de válvula foi introduzida por Georgeson et al. como procedimento prévio ao alongamento intestinal em crianças. Os autores construíram uma válvula por intussuscepção de um segmento do intestino delgado, que foi separado do mesentério por uma distância de $8 \mathrm{~cm}$, seccionado e dobrado sobre si mesmo. Meses depois, os pacientes foram submetidos a procedimentos de alongamento intestinal ${ }^{18}$. Esse tipo de válvula tem os inconvenientes da perda de uma porção significativa do intestino delgado e de não proporcionar uma obstrução intestinal controlável.

A técnica cirúrgica aqui proposta criou duas válvulas, cada uma delas resultado de seromiotomias circunferenciais duplas, separadas por $2 \mathrm{~mm}$ de parede intestinal íntegra. A borda cruenta proximal da seromiotomia cranial era suturada à borda cruenta distal da seromiotomia caudal com pontos separados. Esse procedimento é simples e não extirpa ou põe em risco segmentos intestinais. As válvulas foram capazes de determinar dilatação intestinal no período pós-operatório em que se deu a eutanásia e não foram observados sinais de obstrução.

Em humanos a resposta adaptativa ainda não está bem caracterizada. Enquanto o aumento na absorção de nutrimentos foi demonstrado, as observações das modificações morfológicas após ressecções não são conclusivas. Ao contrário, as alterações morfológicas e funcionais decorrentes de ressecção intestinal maciça em ratos estão determinadas ${ }^{19}$. Esses roedores são modelos muito utilizados para o estudo da 


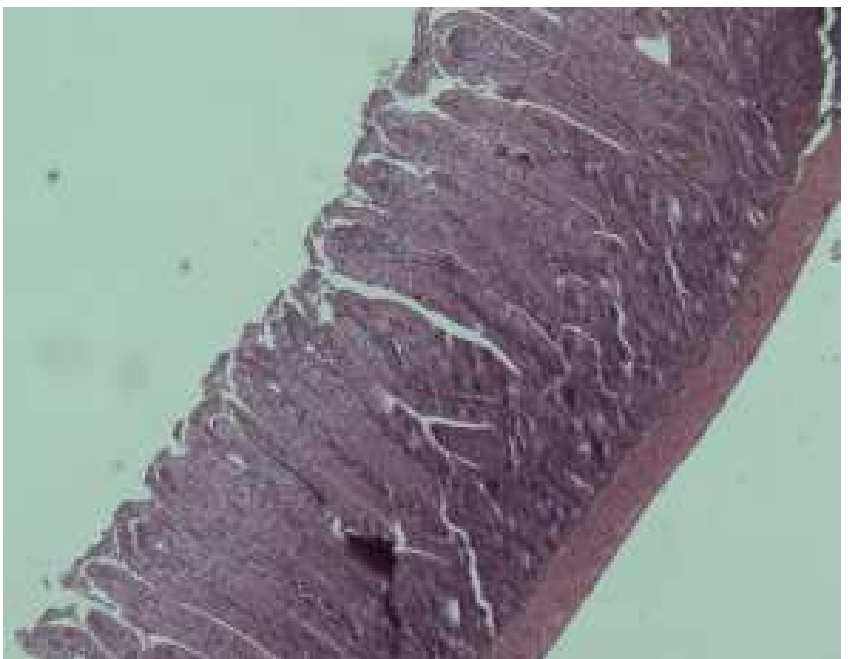

Figura 4 - Fotomicrografia dos vilos intestinais alongados em animal submetido à ressecção intestinal e criação de válvula (Grupo RV). Aspecto do segmento intestinal distal à segunda válvula. $H E, 5 X$.

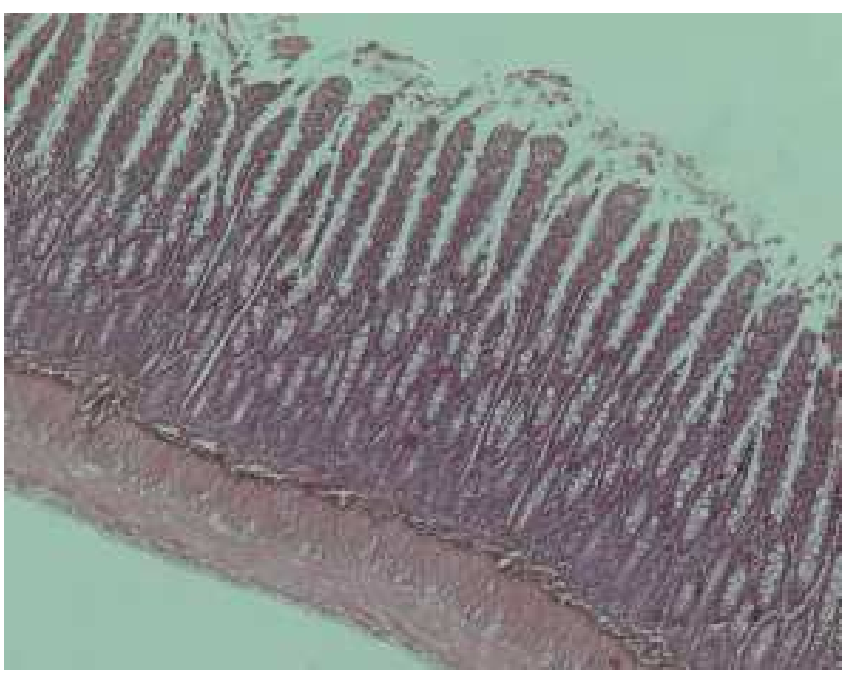

Figura 5 - Fotomicrografia dos vilos intestinais alongados em animal submetido à confecção de válvula, sem ressecção intestinal (Grupo $V$ ). Aspecto segmento intestinal distal à segunda válvula. $H E, 5 X$.

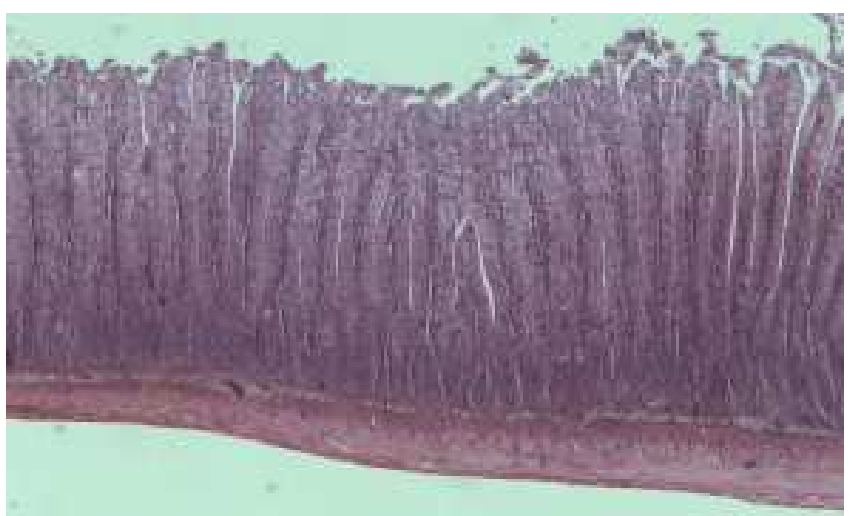

Figura 6 - Fotomicrografia dos vilos intestinais alongados em animal submetido à ressecção intestinal e criação de válvula (Grupo RV). Aspecto do segmento intestinal distal à segunda válvula. HE, $5 X$.

fisiopatologia e das opções de tratamento da SIC e da adaptação intestinal ${ }^{20-25}$. Ressaltando-se os cuidados na extrapolação dos achados, no presente trabalho optou-se pelo uso de ratos, animais de fácil criação e manejo.
Neste estudo o comprimento do intestino delgado foi medido nos animais dos Grupos R e RV, a fim de calcular o comprimento correspondente aos $50 \%$ a serem ressecados. Com os valores mínimo de $69 \mathrm{~cm}$ e máximo de $110 \mathrm{~cm}$, o valor médio encontrado foi de $88,7 \pm 10,1 \mathrm{~cm}$, inferior ao relatado por Guerra e Peters ${ }^{26}$. Considerando-se que o íleo corresponde a $10 \%$ do comprimento do intestino delgado de ratos $^{27} \mathrm{e}$ que as ressecções intestinais eram proximais, o segmento ressecado era histologicamente diferente da região das seromiotomias ( $15 \mathrm{~cm}$ e $10 \mathrm{~cm}$ da válvula ileocecal). Isso levou à criação do Grupo C, composto por animais que forneceram amostras de segmentos intestinais para comparação dos vilos.

O aumento da altura dos vilos é um parâmetro clássico na avaliação morfológica da adaptação intestinal. Após ressecções intestinais os vilos sofrem um alongamento resultante da hiperplasia e hipertrofia celulares ${ }^{1,28-30}$. Nygaard observou hipertrofia intestinal difusa em ratos submetidos a ressecções de $50 \%$ e $75 \%$ do intestino delgado, mas apenas no sítio da anastomose em animais com $25 \%$ do intestino ressecado $^{31}$. Em trabalho posterior, Hanson et al. observaram que o intestino apresenta hiperplasia de todas as camadas após ressecção de $25 \%$, porém mais discreta que a encontrada naqueles com ressecções de $50 \%$ e $80 \%{ }^{32}$. Com base nesses relatos, as amostras intestinais no presente trabalho eram provenientes de animais submetidos à ressecção de $50 \%$ do intestino delgado, com ou sem a criação de válvulas (Grupos R, RV e V). Foram realizadas medidas da altura de cinco vilosidades íntegras e bem orientadas de cada segmento estudado. A técnica utilizada para medir a altura dos vilos está bem estabelecida na literatura, com autores optando por medir dez ${ }^{33}$, cinco $^{11,20,34}$ ou apenas três delas ${ }^{35}$.

A hiperplasia inicia-se 24 horas a 48 horas após a ressecção, dando início à adaptação intestinal. O alongamento intestinal é mínimo, mas os aumentos no diâmetro da alça intestinal e no comprimento dos vilos são acentuados, ampliando efetivamente a superfície absortiva ${ }^{32,36,37}$. Dowling e Booth observaram hipertrofia mucosa e maior absorção de glicose no remanescente intestinal de ratos Wistar submetidos a ressecções de $75 \%$ do intestino delgado. As alterações, mais proeminentes no íleo que no jejuno, desenvolveram-se duas semanas após a operação ${ }^{20}$. Em outro trabalho, com ratos wistar, após colectomia subtotal com anastomose íleo-retal, a altura dos vilos ileais era superior à do grupo controle no sétimo dia pós-operatório ${ }^{38}$. Em ratos Holtzman, o aumento no número de células nas criptas e nos vilos e na espessura de todas as camadas intestinais foi evidenciado dois dias após a ressecção intestinal. Os valores máximos foram alcançados no $12^{\circ}$ dia e eram similares aos encontrados no $30^{\circ}$ dia pósoperatório $^{32}$. Em publicação recente, a avaliação morfométrica de criptas e vilos do intestino de camundongos foi realizada com sete dias de ressecção do intestino delgado ${ }^{28}$. Na presente casuística, os animais foram mortos entre o décimo e o $14^{\circ}$ dias de pós-operatório, dentro do período de alterações morfométricas mais acentuadas. Nos grupos tratados houve aumento no comprimento dos vilos, comparados ao controle, e no diâmetro da alça intestinal, comparado ao diâmetro préoperatório do mesmo animal. 
Os vilos aumentaram de comprimento, sem diferença estatística, nos animais submetidos ou não à ressecção intestinal, com ou sem a criação das válvulas. Isoladamente, o fato de as válvulas não interferirem negativamente no alongamento dos vilos nos grupos com ressecção já seria significativo. Mais do que isso, quando as válvulas foram construídas sem ressecção intestinal os vilos também foram mais longos que os do controle, ou seja, as válvulas constituíram um fator de aprimoramento para um dos parâmetros de adaptação intestinal. Esses achados corroboram a opinião de que a operação precoce, com técnicas que facilitem a adaptação natural do intestino, deve ser considerada ${ }^{3,4}$, a despeito do temor, manifestado em trabalhos anteriores ${ }^{39,40}$, de interferência negativa no processo adaptativo, que protelava os procedimentos cirúrgicos para a fase tardia.

A ressecção intestinal é o mais importante estímulo para a hiperplasia mucosa e tanto a extensão da ressecção quanto o segmento ressecado interferem no grau de adaptação. Ressecções mais extensas provocam respostas compensatórias mais exuberantes e a hipertrofia mucosa é mais pronunciada após ressecção proximal ${ }^{20,31,32,41-43}$. A diferença segmentar da adaptação pode estar relacionada a fatores múltiplos, incluindo a perda de células sítio-específicas, produtoras de hormônios tróficos, como as células "L" do íleo e do colo, e mudanças no volume e composição do conteúdo luminar $1,2,20,21,31,33,44,45$.

No Grupo RV, os vilos do segmento proximal tiveram comprimento superior ao do segmento distal. O contrário ocorreu no Grupo V, no qual o comprimento dos vilos do segmento proximal foi menor que o do segmento distal, porém sem diferença significativa. $\mathrm{O}$ encurtamento do intestino pode explicar esse resultado. Em condições normais, dada a absorção jejunal, uma quantidade pequena de nutrimentos alcança o íleo. Após ressecção intestinal extensa ou translocação jejuno-ileal, o íleo recebe conteúdo quase que diretamente do estômago e do duodeno. Em ambas as situações o íleo exibe hiperplasia, sugerindo que a nutrição intraluminar desempenha um papel importante como fator de regulação no crescimento mucoso 20,31,33,45. Um maior aporte de secreções biliopancreáticas, especialmente pancreáticas, é outro fator luminar envolvido ${ }^{1,21,44}$.

A dilatação é um segundo parâmetro morfológico de adaptação intestinal. Nesse estudo ela tanto resultou da ressecção intestinal isolada quanto da criação das válvulas, com ou sem ressecção, sem diferença significativa. Nenhum dos animais apresentou sinais clínicos de obstrução intestinal.

Uma questão é se a dilatação decorreria simplesmente da obstrução parcial ou se as válvulas promoveriam adaptação, com indução de verdadeiro crescimento intestinal. Em 2007, Rena et al. publicaram o estudo da morfometria das camadas longitudinal e circular do intestino dos animais que constituíram o Grupo $\mathrm{V}$ do presente trabalho. $\mathrm{O}$ aumento da camada muscular, em comparação com o controle, não ultrapassou 2,09 vezes no músculo circular e 2,34 vezes no longitudinal $^{8}$. Uma estenose cirúrgica levou ao aumento superior a dez vezes na camada muscular do intestino de animais ${ }^{46}$. Esses dados indicam que os mecanismos ora criados a partir de seromiotomias constituem, sim, válvulas e não estenoses cicatriciais. Anteriormente, métodos de imagem (trânsito de intestino e colonoscopia) já haviam mostrado a função valvular de seromiotomias circunferenciais duplas em humanos ${ }^{6,7}$.

Fatos relevantes são o alongamento dos vilos e o aumento do diâmetro no segmento intestinal distal à segunda válvula, mesmo em animais sem ressecção intestinal. Situação similar foi observada por Barra no segmento distal do intestino de ratos submetidos à criação de uma única válvula por seromiotomias circunferenciais, sem ressecção intestinal $^{9}$. A localização aboral dessa porção do intestino delgado em relação à barreira mecânica representada pelas válvulas sugere a atuação de outros fatores que não apenas os locais e luminares.

A desnervação química do plexo mioentérico provocou aumento no comprimento dos vilos e no diâmetro da alça intestinal de ratos, inclusive distalmente ao segmento tratado. A ressecção intestinal seguida de reversão de segmento em ratos também resultou no aumento desses parâmetros no segmento distal à reversão ${ }^{47}$. Mudanças na atividade mioelétrica podem ter alterado o circuito neural entre os plexos mioentérico e submucoso. O plexo submucoso tem forte influência sobre a circulação sanguínea da mucosa e há uma interconexão recíproca entre os dois plexos. A interrupção do plexo mioentérico resulta no aumento do aporte sanguíneo mucoso. Ocorrem alterações na liberação de neurotransmissores como conseqüência da interferência na rede neural entre os plexos, influenciando na morfologia da alça $a^{21,47}$. Embora para a construção das válvulas por seromiotomia circunferencial apenas segmentos lineares da camada seromuscular sejam seccionados, há interrupção da conexão entre os plexos nesses pontos.

Apesar dos resultados morfológicos favoráveis à adaptação intestinal, a ressecção do intestino levou à perda de peso nos animais com ou sem válvulas. A perda não foi significativa quando comparada aos pesos pré-operatórios e foi estatisticamente semelhante entre os grupos. O curto período de tempo entre a operação e a eutanásia poderia justificar esse resultado. Estudos em ratos ${ }^{48}$, cães $^{16,49,50}$ e humanos ${ }^{6,49}$ mostraram que as válvulas artificiais tornam o trânsito intestinal mais lento e promovem ganho ponderal após ressecções intestinais. Willis et al. avaliaram o efeito de válvulas artificiais na adaptação intestinal de ratos com ressecção proximal ou distal ${ }^{23}$. A citometria de DNA mostrou que as válvulas levaram à hiperplasia celular e ao alongamento dos vilos. A capacidade absortiva dos enterócitos não foi influenciada pelas válvulas e não houve ganho de peso corporal até a eutanásia, efetuada no décimo dia pós-operatório. Ao contrário, a construção de uma válvula jejunal levou ao ganho de peso ratos, com ressecção intestinal, bem como a uma menor taxa de mortalidade, quando a eutanásia deu-se com três meses ${ }^{48}$. Schiller et al. observaram menor perda de peso em cães submetidos à ressecção intestinal acompanhada de um esfíncter artificial quando comparados com aqueles submetidos somente à ressecção ou ressecção mais interposição de segmento antiperistáltico. Esses animais também foram mortos tardiamente, entre $109^{\circ}$ e $198^{\circ}$ dia pós-operatório ${ }^{16}$. Trabalhos futuros, com eutanásia programada para depois do décimo dia de operação poderiam avaliar melhor esse resultado. 
Os resultados obtidos nos experimentos indicam que as válvulas intestinais por seromiotomias circunferenciais não são fatores de interferência negativa na adaptação intestinal após ressecção. Ao contrário, parecem influenciá-la de forma positiva. A técnica é de fácil execução e não compromete longos segmen- tos intestinais, vitais quando o intestino remanescente é muito curto. Por não ocasionarem obstrução e permitirem alongamento dos vilos, essas válvulas podem ser incluídas entre as técnicas de reabilitação intestinal cirúrgica, isoladamente ou precedendo intervenções de alongamento do intestino.

\begin{abstract}
Background: to evaluate the role of artificial valves created by double circumferential seromyotomies in the villi length, in the small intestine diameter and in the weight of rats. Method: 40 rats have been distributed into four groups. The $R$ Group animals were submitted to the resection of 50\% of the small intestine, without the creation of valves. In the RV Group, two valves were associated to intestinal resection. In the V Group, two valves were created, without intestinal resection. The C Group provided the villi average height. Euthanasia was performed between 10 and 14 days after surgery. Results: there has been an increase in villi length in Groups $R, R V$ and $V$. Compared to the $R$ Group, the proximal segment villi length was greater than the distal one. In V Group, the proximal segment villi length was smaller than the distal one. The intestine had a larger diameter than in the presurgical in $R$ Group, and in the segments proximal to the first valve and distal to the second one, in Groups RV and V. Intestinal resection led to weigh loss in Groups $R$ and $R V$, without differences among the groups. In $V$ Group there has been significant weight gain compared to groups $R$ and $R V$. Although they did not prevent weight loss in the animals submitted to resection, the valves did not cause greater loss than that of the resection itself, isolated. Conclusion: these valves seem to positively interfere in intestinal adaptation and might be included among the techniques of surgical intestinal rehabilitation, isolated or preceding interventions of intestine lengthening.
\end{abstract}

Key words: Small intestine; Short bowel syndrome; Artificial sphincters; Bowel resection; Intestinal Mucosal.

\section{REFERÊNCIAS}

1. Wilmore DW, Byrne TA, Persinger RL. Short bowel syndrome: new therapeutic approaches. Curr Probl Surg. 1997; 34(5):392444.

2. Cisler JJ, Buchman AL. Intestinal adaptation in short bowel syndrome. J Invest Med. 2005; 53(8):402-13.

3. Bianchi A. From the cradle to enteral autonomy: the role of autologous gastrointestinal reconstruction. Gastroenterology. 2006; 130(2):S138-46.

4. Bianchi A. Autologous gastrointestinal reconstruction for short bowel syndrome. Br J Hosp Med. 2007; 68(1):24-7.

5. Wallis K, Loyd DA, Gabe, MS. Promoting intestinal adaptation. Br J Hosp Med. 2007; 68(1):11-4.

6. Rena CL, Lázaro da Silva A, Barra AA, Melo GE, Paula WT. Seromiotomia dupla no intestino delgado: tentativa de criação de um piloro artificial. Rev Col Bras Cir. 1996; 23(3):143-7.

7. Rena CL. Uma proposta cirúrgica auxiliar no tratamento da síndrome do intestino curto: seromiotomia dupla no intestino delgado com criação de um piloro [dissertação]. Belo Horizonte (MG): Academia Mineira de Medicina, 2002.

8. Rena CL, Lázaro da Silva A, Barra AA, Furtado MCV, Rena RL, Rena RL. Alterações morfométricas da musculatura dos músculos longitudinal e circular de ratos submetidos à criação de piloros no intestino delgado. Rev Col Bras Cir. 2007; 34(1):41-7.

9. Barra AA. Estudo das vilosidades em segmentos do intestino de ratos após a confecção de esfíncteres [dissertação] Belo Horizonte (MG): Universidade Federal de Minas Gerais; 2007.

10. Wolfensohn S, Lloyd M. Anesthesia of laboratory animals. In: Handbook of Laboratory Animal Management and Welfare. $3^{\text {rd }}$ ed. Oxford: Blackwell Publishing; 2003. p.107-37.

11. Sencan A, Akçora B, Mir E, Sencan A, Günsar C, Arslan O, Özer E. Does ileal reverse segment in rats with short bowel syndrome change intestinal morphology? J Pediatr Gastroenterol Nutr. 2002; 34(2):165-8.
12. Irving M. Intestinal failure. J Gastroenterol Hepatol. 2000; 15 Suppl:G26-9.

13. Thompson JS. Edgar J. Poth Memorial Lecture. Surgical aspects of the short-bowel syndrome. Am J Surg. 1995;170(6):532-6.

14. Iglesias ACR, Silva OC Jr, Ceneviva R. Surgical management of short bowel syndrome. Acta Cir Bras. 1995; 10(3):135-43.

15. Glassman JA. An artificial ileocecal valve. Surg Gynecol Obstet. 1942; 74(1):92-8.

16. Schiller WR, DiDio LJ, Anderson MC. Production of artificial sphincters. Ablation of the longitudinal layer of the intestine. Arch Surg. 1967; 95(3):436-42.

17. Lázaro da Silva A. Tentativa de tratamento do "dumping" através de um "esfíncter" ileal. Rev Assoc Med Minas Gerais. 1974; 25(1):32-3.

18. Georgeson K, Halpin D, Figueroa R, Vincent Y, Hardin Jr W. Sequential intestinal lengthening procedures for refractory short bowel syndrome. J Pediatr Surg. 1994; 29(2):316-21.

19. Drozdowski L, Thomson AB. Intestinal mucosal adaptation. World J Gastroenterol. 2006; 12(29):4614-27.

20. Dowling RH, Booth CC. Structural and functional changes following small intestinal resection in the rat. Clin Sci. 1967; 32(1):139-49.

21. Altmann GG, Leblond CP. Factors influencing villus size in the small intestine of adult rats as revealed by transposition of intestinal segments. Am J Anat. 1970; 127(1):15-36.

22. Wathen LM, Osborne JW, Loven DP. Effect of two intestinal resections separated by time on cell proliferation in rat small intestine. Gastroenterology. 1981; 80(6):1535-41.

23. Willis S, Klosterhalfen B, Titkova S, Anurov M, Polivoda M, Max M, Öttinger AP, Schumpelick V. Effect of artificial valves on intestinal adaptation in the short-bowel syndrome: an integrated study of morphological and functional changes in rats. Eur Surg Res. 2000; 32(2):111-9.

24. Fagundes DJA, Taha MO. Modelo animal de doença: critérios de escolha e espécies de uso corrente. Acta Cir Bras. 2004; 19(1):59-65. 
25. Schanaider A, Silva PC. Uso de animais em cirurgia experimental. Acta Cir Bras. 2004; 19(4):441-7.

26. Guerra MG, Peters VM. Comprimento do intestino delgado e trânsito intestinal em ratas Wistar. Boletim do Centro de Biologia da Reprodução.1995; 14:47-50.

27. DeSesso JM, Jacobson CF. Anatomical and physiological parameters affecting gastrointestinal absorption in humans and rats. Food Chem Toxicol. 2001; 39(3):209-28.

28. Haxhija EQ, Yang H, Spencer AU, Sun X, Teitelbaum DH. Intestinal epithelial cell proliferation is dependent on the site of massive small bowel resection. Pediatr Surg Int. 2007;23(5):379-90.

29. Iglesias ACRG, Zucoloto S, Vannucchi H, Cenevita R. Mecanismos de adaptação intestinal e suas relações com a ressecção extensa do intestino delgado. Rev Col Bras Cir. 1993; 20(1):34-41.

30. Iglesias ACRG, Zucoloto S. Proliferação celular do epitélio intestinal: mecanismos de adaptação e controle após ressecção extensa do intestino delgado. Medicina (Ribeirão Preto). 1994; 27(3/ 4):303-9.

31. Nygaard K. Ressection of the small intestine in rats. III. Morphological changes in the intestinal tract. Acta Chir Scand. 1967; 133(3):233-48.

32. Hanson WR, Osborne JW, Sharp JG. Compensation by the residual intestine after intestinal resection in the rat. I. Influence of amount of tissue removed. Gastroenterology. 1977; 72(4):692700 .

33. Gleeson MH, Cullen J, Dowling H. Intestinal estructure and function after small bowel by-pass in the rat. Clin Sci. 1972; 43(6):731-42.

34. Altmann GG, Enesco M. Cell number as a measure of distribution and renewal of epithelial cells in the small intestine of growing and adult rats. Am J Anat. 1967; 121(2):319-36.

35. Tramonte R, Carvalho ROM, Farias DC, Serafim JDM, Ortellado DK, d'Acampora AJ. Alterações da mucosa intestinal em ratos. Estudo morfométrico em três diferentes tratamentos após indução experimental de sepse abdominal aguda. Acta Cir Bras. 2004; 19(2):120-5.

36. Vanderhoof JA, Langnas AN. Short-bowel syndrome in children and adults. Gastroenterology. 1997; 113: 1767-78.

37. Misiakos EP, Macheras AM, Kapetanakis T, Liakakos T. Short bowel syndrome: current medical and surgical trends. J Clin Gastroenterol. 2007; 41(1): 5-18.

38. Woo ZH, Nygaard K. Small-bowel adaptation after colectomy in rats. Scand J Gastroenterol. 1978; 13(8):903-10.

39. Thompson JS. Surgical rehabilitation of intestine in short bowel syndrome. Surgery. 2004; 135(5):465-70.
40. DiBaise JK, Young RJ, Vanderhoof JA. Intestinal rehabilitation and short bowel syndrome: part 2. Am J Gastroenterol. 2004; 99(9):1823-32.

41. Skála I, Hromádková V, Skála J. Hypertrophy of small intestine after its partial resection in the rat-size of the mucosal surface. Digestion. 1969; 2(1):23-34.

42. Hanson WR, Osborne JW, Sharp JG. Compensation by the residual intestine after intestinal resection in the rat. II. Influence of postoperative time interval. Gastroenterology .1977; 72(4 Pt 1):701-5.

43. Williamson RC. Intestinal adaptation (first of two parts). Structural, functional and cytokinetic changes. N Eng J Med. 1978; 298(25):1393-402.

44. Altmann GG. Influence of bile and pancreatic secretions on the size of intestinal villi in the rat. Am J Anat. 1971; 132(2):167-77.

45. Grönqvist B, Engström B, Grimelius L. Morphological studies of the rat small intestine after jejuno-ileal transposition. Acta Chis Scand. 1975; 141(3):208-17.

46. Gabella G. Hypertrophy of intestinal smooth muscle. Cell Tissue Res. 1975; 163(2):199-214.

47. Sencan A, Mir E, Karaka I, Akçora B, Sencan A, Özer E. Effects of intrinsic denervation on intestinal morphology in rats with short-bowel syndrome. Pediatr Surg Int. 2000; 16(8):554-8.

48. Careskey J, Weber TR, Grosfeld JL. Ileocecal valve replacement. Its effect on transit time, survival, and weight change after massive intestinal resection. Arch Surg. 1981; 116(5):618-22.

49. Blanco-Benavides R, Niño J. Construction of a new intestine valve. Dis Colon Rectum. 1994; 37(6):606-9.

50. Stacchini A, DiDio LJ, Primo ML, Borelli V, Andretto R. Artificial sphincters as surgical treatment for experimental massive resection of small intestine. Am J Surg. 1982; 143(6):721-6.

Como citar este artigo:

Furtado MC, Silva AL, Rena CL, Barra AA, Felga AM, Rossman FM. Influência de válvulas artificiais sobre a morfometria intestinal de ratos. Rev Col Bras Cir. [periódico na Internet] 2008; 35(5). Disponível em URL: http://www.scielo.br/rcbc

Maria Cristina Vasconcellos Furtado

Rua Dr. Romualdo, 420/402

Bairro São Mateus

36016-380 - Juiz de Fora- MG

E-mail: mcvf@ superig.com.br

cristina.furtado@ufjf.edu.br

Telefones: (32) 8844-9344 e 3212-0313 